التأثير الأليلوياثي للمخلفات النباتية لبعض المحاصيل في أنبات ونمو أربعة أنواع من الأدغال

$$
\text { وسن صالح حسين }
$$$$
\text { (أستلم 2013/11/11 ؛ قُبل 2014/1/ }
$$

الملخص

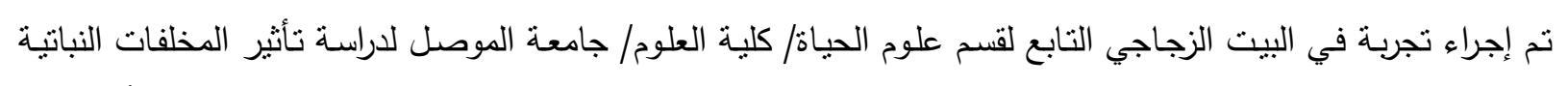

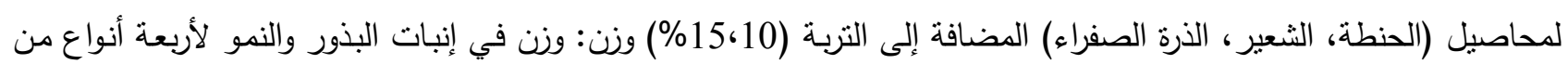

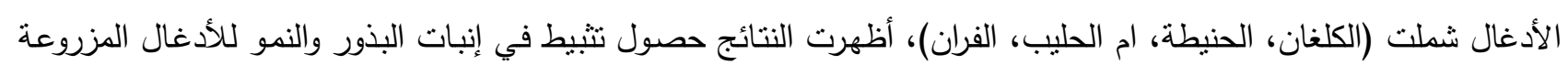

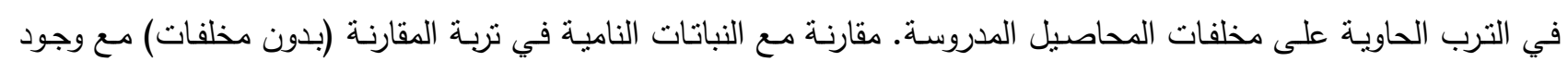

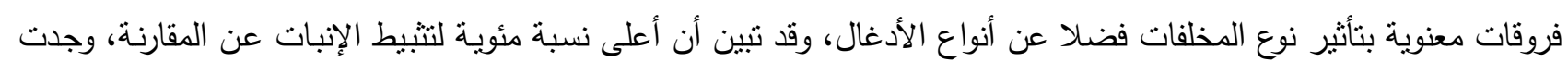

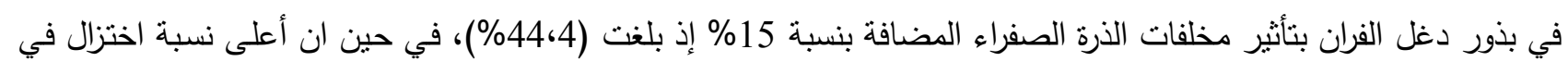

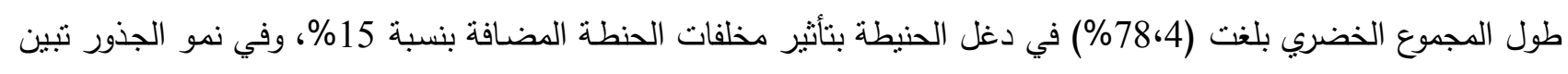

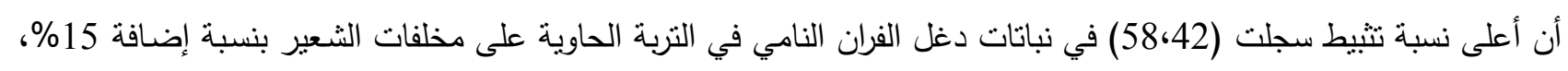

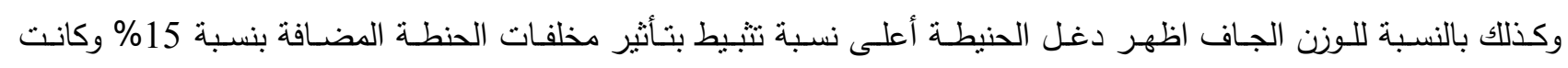

كما تثير النتائج إلى تباين مخلفات المحاصيل الثثلاثة في إظهار تأثيرها الاليلوباثي فضلا عن تباين الأدغال في استجابتها

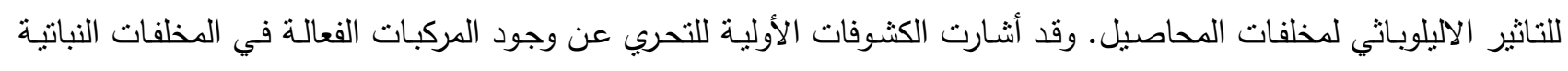

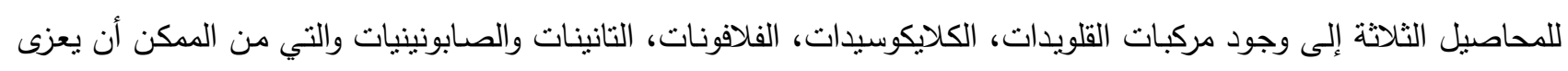

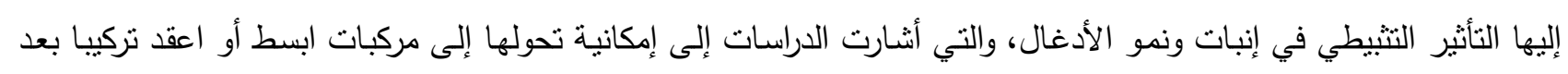
تحررها إلى التربة. الكلمات الدالة: الأليلوباثي، الأدغال، الحنطة، زهرة الثمس.

\title{
Allelopathic Effect of some Crops Residues on Germination and Growth of Four Weed Species
}

\author{
Wasan H. Salih Janan A. Saeed \\ Department of Biology/ College of Science/ \\ University of Mosul \\ Amer M. Al-Mathedy \\ Department of Biology/College of Education/ \\ University of Mosul
}

\begin{abstract}
This study was conducted in the glasshouse in Biology Depertment\College of Sciences Mosul University to study the effect of the crops (wheat, Barley, corn) residues that added to the soil at ratio $(10,15 \%) \mathrm{W}: \mathrm{W}$ in seed germination and growth of four weeds includes (Silybum marianum L., Lolium rigidum. L., Sonchus oleraceus L., Panicum Spp.). The results showed inhibition in seed germination and growth of the weeds growing in the soil containing the crops residues compared with the plant (weeds) growing in control soil (with out residues). Also the result
\end{abstract}




$$
\text { وسن صالح حسين وآخرون }
$$

showed variation in the crops allelopathic effect on germination and growth of the weeds treated with the crops residues. Moreover, the results show a difference in allelopathic effect of the crops residues, in addition the weed species differ in their response to the effect There is significant difference between the type of residues rather than weed species, it was found that the highest inhibition in seed germination was in (Panicum) seeds affected by corn residues added at ratio 15\% which reached up to (44.4), while in the growth of the weeds, the highest reduction in shoot length recorded (78.4) noticed in Lolium at the ratio $15 \%$ of Wheat residues but in the root length highest reduction recorded (58.4\%) noticed in Panicum at the ratio $15 \%$ of Barley residues ,in dry weight the highest inhibition noticed in Lolium affected by Wheat residues added at ratio $15 \%$ whicht reached up to (95.18). The initial detection of the active compounds in the crops residues indicate the exsistance of the compounds include (Alkaloids, Glycosides, Flavonoids, Tannins and Saponins) which had inhibition effect and can be converted to simpler or more complicated forms after being released to the soil.

Keywords: Allelopathy, Weed, Wheat, Sunflower.

\section{المقدمة}

تعد الأدغال من المشاكل الثنائعة التي تواجه الزراعة في معظم دول العالم إضافة إلى كونها تتافس المحاصيل على الضوء والغذاء والرطوبـة والموقع مسببة قلـة في الإنتاج والحاصل لذلك يتوجب مكافحتها، ومن الطرائق الثـائعة في مكافحـة الأدغال

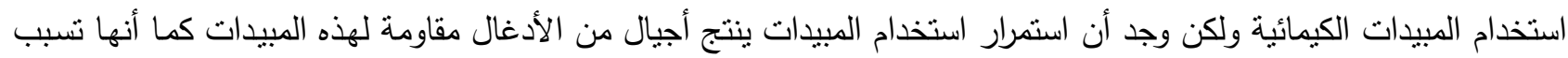
تلوثا للبيئة، ولهذه الأسباب توجهت الأبحاث في السنوات الأخيرة إلى إيجاد بديل يكون أكثر نفعا، فاتجهت الأنظار إلى وجود أنواع التهاع من النباتات التي تتتج نواتج ايضية ثنانوية An et al., 1997) Secondary metabolites) تحدث من خلال إنتاج مركبات كيمائية تؤثر في الإنبات والنمو والنكاثر في الكائنات الأخرى وسميت هذه المركبات Allelochemicals. وقد عرف الاليلوباني

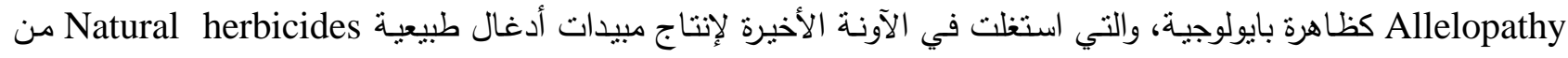
خلال التداخل البايوكيمائي بين أنواع من النباتات (Samad et al., 2008)باستخدام المركبات المتحررة من الأجزاء النباتية المختلفة التي تؤثز في جميع مراحل حياة النبات ابتداء من أنبات البذرة وصولا إلى مرحلة النضج، اذ أصبحت هذه الظاهرة هي

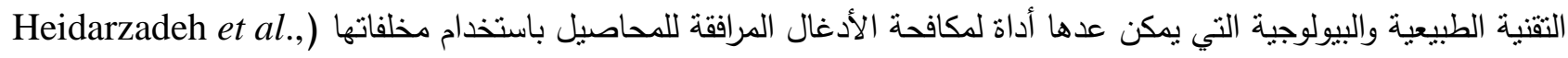
2010)، كما وتعد التكنولوجيا المناسبة للسيطرة على الأدغال باستخدام المركبات الكيمائية المتحررة من الأجزاء النباتية المختلفة بهاء للمحاصيل (Naseem et al., 2009)، ومن هذه المحاصيل هي الحنطة، الثعير ، الثوفان، الذرة، زهرة الثمس، الرز وغيرها والتي تعرف بامتلاكها جها اليلوباثيا في الحد والسيطرة على نمو الأدغال. وان الغاية من استخدام هذه المحاصيل في السيطرة

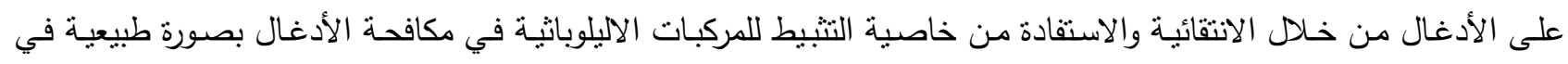

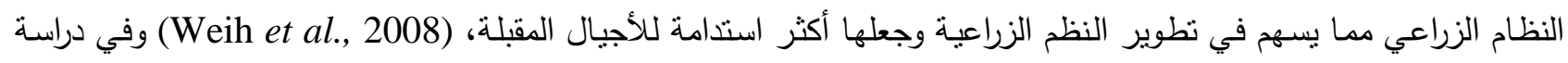
أجراها (2009) Goran and Sakri لمعرفة التأثير الاليلوباثي لمخلفات صنفين من الثعير (ابيض، اسود) لاحظا حصول

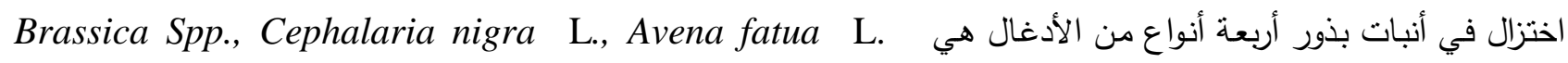
Echinochtoa cras

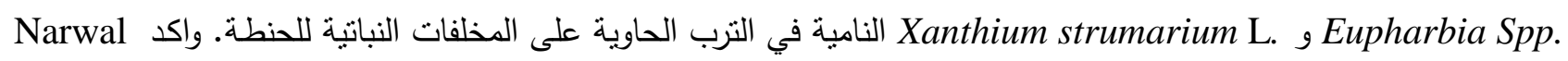
بان بعض المحاصيل الصيفية (الذرة الصفراء و البيضـاء و زهرة الثمس) والمحاصيل الثـتوية

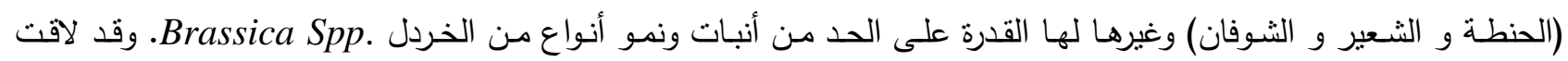

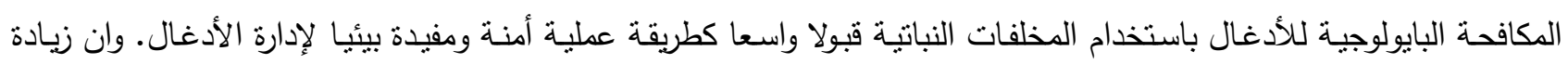


الاهتمام بهذه الطريقة يرجع الى التأثير السلبي للطرق المتبعة على البيئة وصحة الإنسان. وتهدف الدراسـة الحالية إلى معرفة

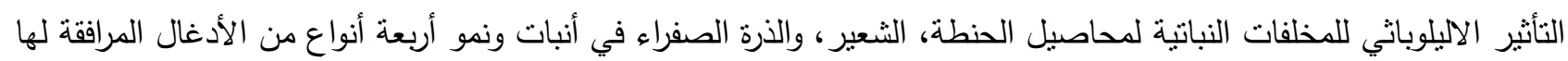

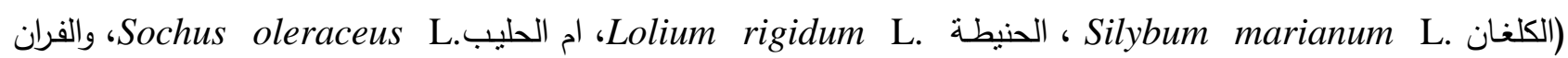

.(Panicum Spp.

\section{مواد البحث وطرائقه}

تضمن البحث اجراء تجربة في البيت الزجاجي التابع لقسم علوم الحياة /كلية العلوم /جامعة الموصل لدراسة تأثير مخلفات

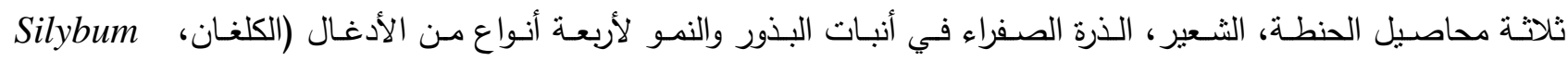

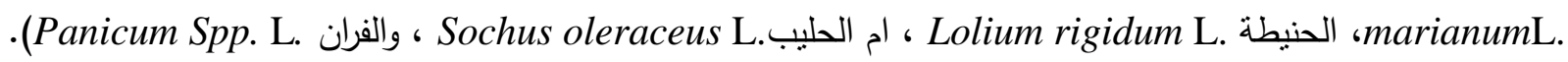

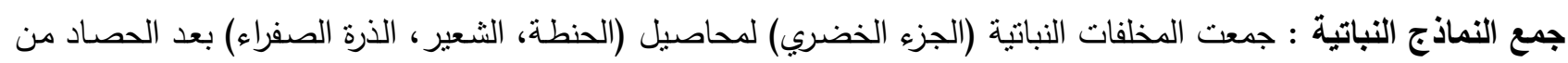

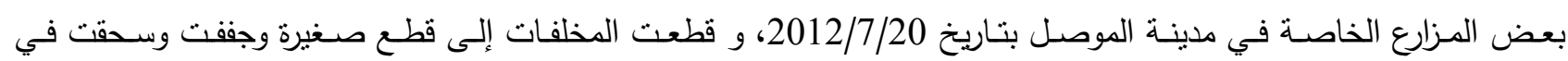
جهاز Blender، وحفظت في أكياس بلاستيكية في الثلاجة.

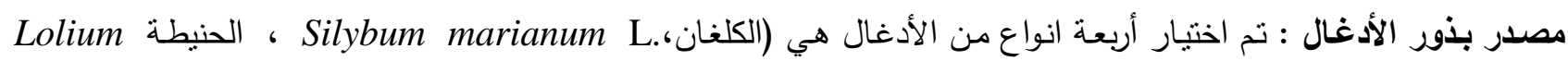

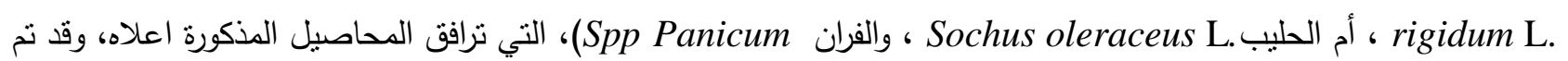
The National Center الحصول على بذور الأدغال من المركز الدولي للبحوث الزراعية والاستدامة المملكة الأردنية الهاشمية ، for Agricultural Research and Extension, Hashemite Kingdom of Jordan الكلغان 89\% والحنيطة 96\% وام الحليب 90\% والفران 98\% . تهيئة التربة المستخدمة في الزراعة : تم مزج مسحوق مخلفات كل من المحاصيل الحنطة، الثعير، الذرة الصفراء مع تربة مزيجية مجففة هوائيا وبنسب إضافة (10 ،15 \%) وزن: وزن، ثم وزعت في أصص بلاستنكية بقطر (20 سم) وارتفاع (25 سم)، واستخدمت أربع مكررات لكل

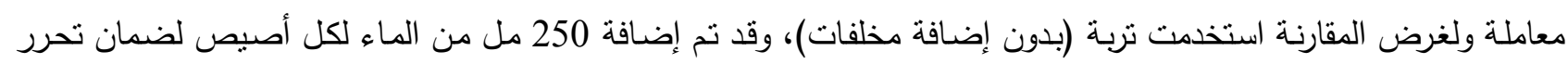
المركبات، وتركت الأصص في البيت الزجاجي لمدة أسبوع واحد وبعد انتهاء فترة التحضين، زرعت 10 بذورة بذرة لكل من الأدغال

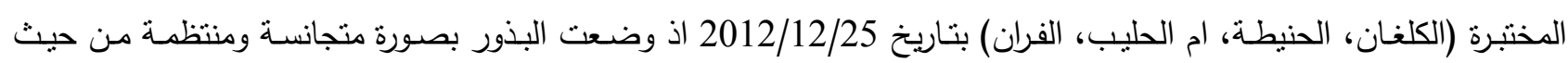

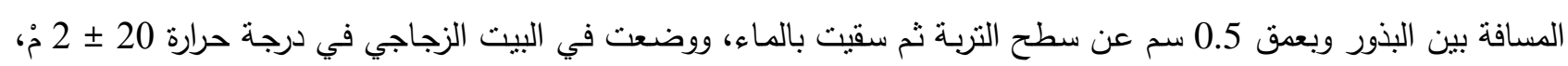
وبعد مرور (15 يوم) من الزراعة، (سعيد، 2010)، تم حساب النسب المئوية للإنبات تبعاً للمعادلة التالية:

$$
\begin{aligned}
& \text { عدد البادرات الظاهرة } \\
& \text { النسبة المئوية للإنبات = _ _ _ ع } 100 \text { (ISTA, 1976) } \\
& \text { عدد البذور المزروعة }
\end{aligned}
$$

وخفض العدد الى (5) بادرات بحيث كانت المسافات منساوية تقريبا بين البادرات المتبقية، وتم سقي النباتات عند الحاجة بكميات

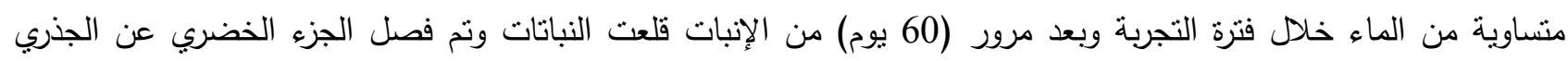

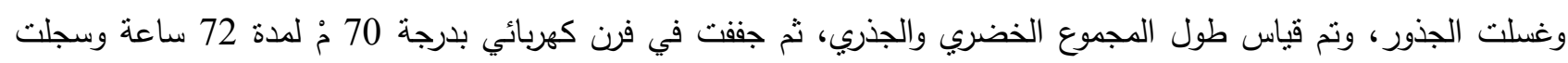
أوزانها الجافة. وتم حساب نسبة التنبيط عن المقارنة (لجميع الصفات) حسب المعادلة التالية : 


$$
\text { وسن صالح حسين وآخرون }
$$

وقد نفذت التجارب حسب تصميم القطاعات العشوائية الكاملة (R.C.B.D.) كتجربة عاملية واجري التحليل الإحصائي للبيانات وفق برنامج SAS، واستخدم اختبار دنكن متعدد المدى عند احتمالية 5\% للتميز بين متوسطات المعاملات (عنتر ، 2010)

\author{
الكثف عن بعض المركبات الفعالة في المخلفات النباتية:$$
\text { 1- الكثف عن الفلافونات: (ال شاكر،2007). }
$$ \\ 2- الكشف عن الصابونينات: (Roopashree et al., 2008) \\ 3- الكشف عن الكلايكوسيدات: (ال شاكر، (2007) \\ 4- الكثف عن القلويدات: حسب طريقة (Harborne, 1973) \\ 5- اكثف عن التانينات: اتبعت طريقة محمد وآخرون(2009) \\ 6- الكثف عن التريينات والستيرويدات: اعتمدت طريقة (Abbas et al., 2012 )
}

\title{
(النتائج
}

من مقارنـة المتوسطات في الجدول (1) يتبين حصول اختزال معنوي في النسبة المئوية لإنبات البذور للأدغال المعاملة

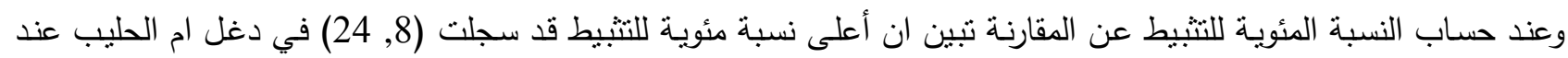
نسبة إضـافة 15\%. في حين أن اقل نسبة تتبيط عن المقارنة لوحظت في دغل الفران عند نسبة الإضـافة 10\% منوسطات نسب الإضافة ظهر أن اقل نسبة أنبات لوحظت عند النسبة 15\%، إذ سجلت (69\%) في دغل الفران، وعن استجابة نوع الأدغال ظهر تباين في التأثر بين الأدغال الأربعة وبهذا يمكن أن نستتتج أن بذور دغل الفران تعد أكثر حساسية للمعاملة إنة بمخلفات المحاصيل في حين ان بذور دغل الكلغان قد أظهرت اقل حساسية، ومن مقارنـة تأثير نوع المخلفات تبين ان مخلفات

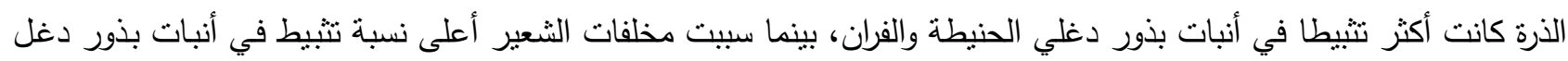

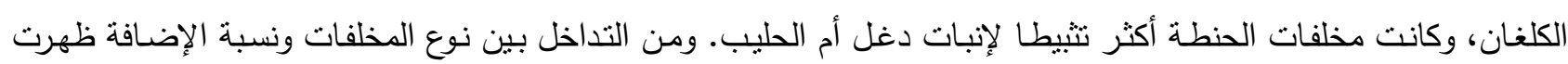

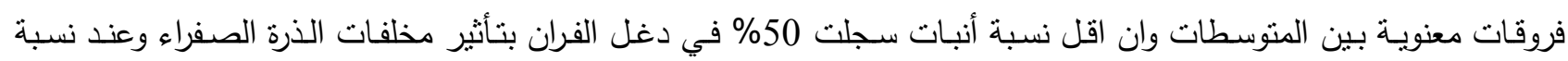
الإضافة 15\% إذ بلغت نسبة التنبيط (44,4). 
الجدول1: تأثثر المخلفـات النباتيـة لـ (الحنطة، الثـعير، الذرة الصفراء) في النسبة المئويـة لإنبات بذور الأدغال (الكلغان، الحنيطة، أم الحليب، الفران).

\begin{tabular}{|c|c|c|c|c|c|c|}
\hline \multirow{2}{*}{ لنسبة الإضثافيط } & \multirow{2}{*}{ متوسط نسبة } & \multicolumn{3}{|c|}{ نوع المخلفات النباتية } & \multirow{2}{*}{ الإضافة } & \multirow{2}{*}{ موع الدغل } \\
\hline & & الأرة الصفراء & الثعير & الحنطة & & \\
\hline 0.0 & $86 a$ & $86 a$ & $86 a$ & $86 a^{*}$ & مقارنة & \multirow{3}{*}{ الكلغان } \\
\hline 12.8 & $75 c$ & $80 \mathrm{~b}$ & $63 c$ & $83 b$ & $\% 10$ & \\
\hline 10.5 & $77 \mathrm{~b}$ & $80 \mathrm{~b}$ & $70 \mathrm{~b}$ & $83 b$ & $\% 15$ & \\
\hline & & $82 \mathrm{ab}$ & $73 c$ & $84 a$ & \multicolumn{2}{|c|}{ تأثير نوع المخلفات } \\
\hline 0.0 & $96 \mathrm{a}$ & $96 a$ & $96 a$ & $96 a$ & مقارنة & \multirow{3}{*}{ الحنيطة } \\
\hline 21.9 & $75 \mathrm{c}$ & $66 \mathrm{~d}$ & $76 \mathrm{c}$ & $83 b$ & $\% 10$ & \\
\hline 18.8 & $78 b$ & $63 \mathrm{e}$ & $76 c$ & $93 a$ & $\% 15$ & \\
\hline & & $75 \mathrm{c}$ & $82 b$ & $90 \mathrm{a}$ & \multicolumn{2}{|c|}{ تأثير نوع المخلفات } \\
\hline 0.0 & $93 a$ & $93 a$ & $93 a$ & $93 a$ & مقارنة & \multirow{3}{*}{ ام الحليب } \\
\hline 17.3 & $77 b$ & $83 b$ & $73 \mathrm{~cd}$ & $76 \mathrm{c}$ & $\% 10$ & \\
\hline 24.8 & $70 \mathrm{c}$ & $83 b$ & $73 \mathrm{~cd}$ & $55 \mathrm{e}$ & $\% 15$ & \\
\hline & & $86 a$ & $79 b$ & $74 \mathrm{c}$ & \multicolumn{2}{|c|}{ تأثير نوع المخلفات } \\
\hline 0.0 & $90 \mathrm{a}$ & $90 \mathrm{a}$ & $90 \mathrm{a}$ & $90 \mathrm{a}$ & مقارنة & \multirow{3}{*}{ الفران الفر } \\
\hline 3.4 & $87 \mathrm{~b}$ & $90 \mathrm{a}$ & $83 c$ & $90 \mathrm{a}$ & $\% 10$ & \\
\hline 23.4 & $69 \mathrm{c}$ & $50 \mathrm{e}$ & $73 d$ & $86 b$ & $\% 15$ & \\
\hline & & $76 \mathrm{c}$ & $82 b$ & $88 \mathrm{a}$ & \multicolumn{2}{|c|}{ تأثثير نوع المخلفات } \\
\hline
\end{tabular}

• الأرقام ذات الأحرف المتثابهة تعني عدم وجود فروقات معنوية بين المعاملات تحت مستوى احتمال 5\% حسب اختبار دنكن متعدد

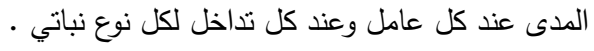

أما النتائج في الجدول (2) تظهر نأثثر مخلفات (الحنطة، الثعير، الذرة الصفراء) في طول المجموع الخضري للأدغال النامية في الترب الحاوية على المخلفات المضافة بنسبة (15،10\%) مقارنة مع الأدغال النامية في نربة المقارنة (بدون مخلفات)، من مقارنة

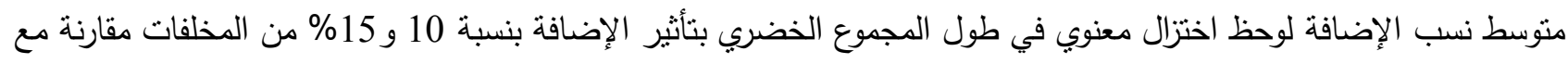

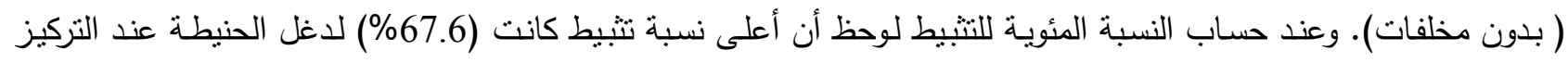

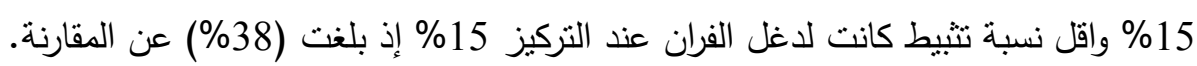

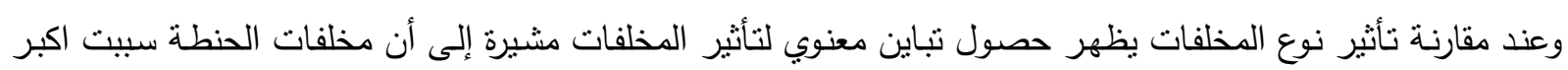

تأثثر تثبيطي في دغلي الكلغان والحنيطة. ومن التداخل بين نوع المخلفات ونسب إضافتها تبين ان اكبر نسبة مئوية للتثبيط عن المقارنة بلغت (78.4\%) في طول

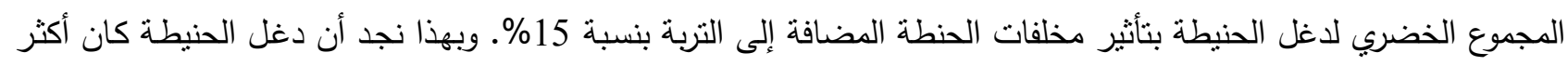
حساسية لتأثير المخلفات النباتية في حين أن دغل الفران كان اقل تأثراً بالمعاملات. 
وسن صالح حسين وآخرون

الجدول 2: تأثير المخلفات النباتية لـ (الحنطة، الثعير ، الذرة الصفراء) في طول المجموع الخضري (سم) للأدغال (الكلغان،

(الحنيطة، ام الحليب، الفران).

\begin{tabular}{|c|c|c|c|c|c|c|}
\hline \multirow[b]{2}{*}{ لنسبة الإضبيط } & \multirow[b]{2}{*}{ متوسط نسبة } & \multicolumn{3}{|c|}{ نوع المخلفات النباتية } & \multirow[b]{2}{*}{ الإضبافة } & \multirow[b]{2}{*}{ نوع الدغل } \\
\hline & & الذرة الصفراء & الشعير & الحنطة & & \\
\hline 00.0 & $5.80 \mathrm{a}$ & $5.8 \mathrm{a}$ & $5.8 \mathrm{a}$ & $* 5.8 \mathrm{a}$ & مقارنة & \multirow[b]{3}{*}{ الكلغان } \\
\hline 48.9 & $3.43 \mathrm{~b}$ & $3.6 \mathrm{~b}$ & $3.5 \mathrm{~b}$ & $3.2 \mathrm{~b}$ & $\% 10$ & \\
\hline 54.2 & $2.66 \mathrm{c}$ & $2.6 \mathrm{c}$ & $2.8 \mathrm{c}$ & $2.6 \mathrm{c}$ & $\% 15$ & \\
\hline & & $4.00 \mathrm{a}$ & $4.03 \mathrm{a}$ & $3.86 \mathrm{~b}$ & \multicolumn{2}{|c|}{ تأثير نوع المخلفات } \\
\hline 0.0 & $22.3 \mathrm{a}$ & $22.3 \mathrm{a}$ & $22.3 \mathrm{a}$ & $22.3 \mathrm{a}$ & مقارنة & \multirow{3}{*}{ الحنيطة } \\
\hline 58.7 & $9.23 \mathrm{~b}$ & $15.3 \mathrm{~b}$ & $5.98 \mathrm{~d}$ & $6.42 \mathrm{~d}$ & $\% 10$ & \\
\hline 67.6 & $7.23 \mathrm{c}$ & $10.9 \mathrm{c}$ & $5.97 \mathrm{~d}$ & $4.83 \mathrm{e}$ & $\% 15$ & \\
\hline & & $16.16 a$ & $11.41 \mathrm{~b}$ & $11.18 \mathrm{~b}$ & \multicolumn{2}{|c|}{ تأثثر نوع المخلفات } \\
\hline 0.0 & $2.35 \mathrm{a}$ & $2.35 \mathrm{a}$ & $2.35 a$ & $2.35 \mathrm{a}$ & مقارنة & \multirow{3}{*}{ ام الحليب } \\
\hline 53.7 & $1.09 \mathrm{~b}$ & $1.67 \mathrm{~b}$ & $0.75 \mathrm{c}$ & $0.87 \mathrm{c}$ & $\% 10$ & \\
\hline 63.9 & $0.85 c$ & $0.92 \mathrm{c}$ & $0.87 \mathrm{c}$ & $0.77 \mathrm{c}$ & $\% 15$ & \\
\hline & & $1.64 \mathrm{a}$ & $1.32 \mathrm{~b}$ & $1.33 \mathrm{~b}$ & \multicolumn{2}{|c|}{ تأثير نوع المخلفات } \\
\hline 0.0 & $3.45 \mathrm{a}$ & $3.45 \mathrm{a}$ & $3.45 \mathrm{a}$ & $3.45 \mathrm{a}$ & مقارنة & \multirow{3}{*}{ الفران } \\
\hline 42.9 & $1.97 \mathrm{c}$ & $1.52 \mathrm{~d}$ & $2.27 \mathrm{bc}$ & $2.12 b c$ & $\% 10$ & \\
\hline 38.0 & $2.14 \mathrm{~b}$ & $2.47 \mathrm{~b}$ & $1.85 \mathrm{c}$ & $2.12 \mathrm{bc}$ & $\% 15$ & \\
\hline & & $2.48 \mathrm{~b}$ & $2.52 \mathrm{ab}$ & $2.56 \mathrm{a}$ & \multicolumn{2}{|c|}{ تأثثير نوع المخلفات } \\
\hline
\end{tabular}

*الأرقام ذات الأحرف المتثابهة تعني عدم وجود فروقات معنوية بين المعاملات تحت مستوى احتمال 5\% حسب اختبار دنكن متعدد المدى عند كل عامل وعند كل تداخل لكل نوع نباتي

وتتشير النتائج في الجدول (3) إلى حصول اختزال في طول المجموع الجذري للأدغال، ومن حسـاب النسبة المئويـة

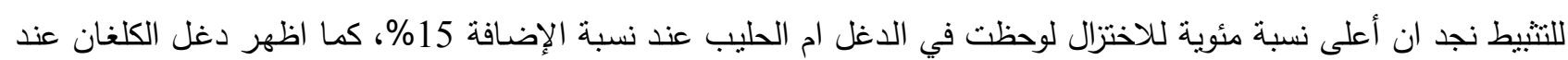
نسبة الإضافة 10\%. اقل نسبة اختزال والبالغة (6.8). وعند مقارنة تأثير نسب الإضافة ظهر اختزال في طول المجموع الجذري بتأثير نسب الإضافة (15,10 \% مقارنة مع معاملة المقارنة (بدون مخلفات)، وعن تأثثر نوع المخلفات يظهر تباين معنوي بين

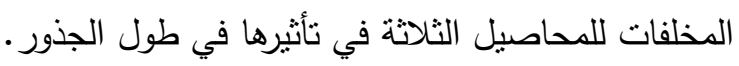
ومن التداخل بين نوع مخلفات المحاصيل ونسبة إضافتها، أظهرت النتائج وجود فروقات معنوية بين المتوسطات لطول فئرل

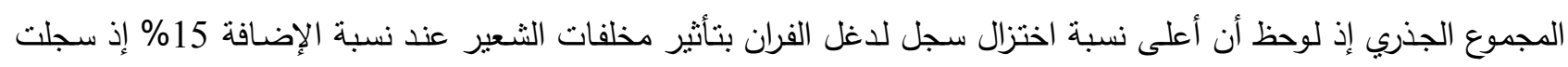

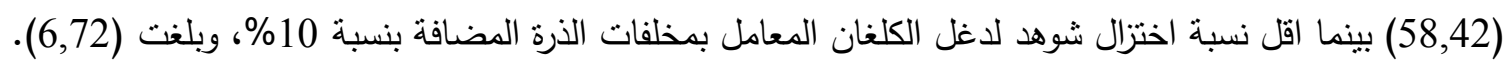

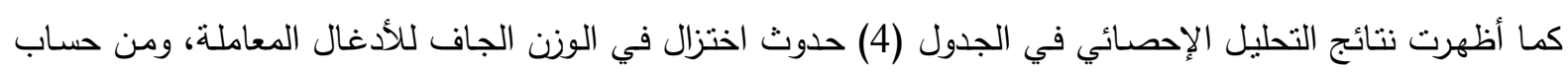
النسبة المئوية للتثبط كانت اعلى نسبة تثبيط في الوزن الجاف لدغل الحنبطة عند نسبة الإضافة 15\% بلغت فئ (85.6) واقل نسبة تثبيط سجلت (35.8) لدغل الفران عند نسبة الإضـافة 10\%. واظهر دغل الحنيطة أعلى نسبة تنبيط في الوزن الجاف بتأثنير

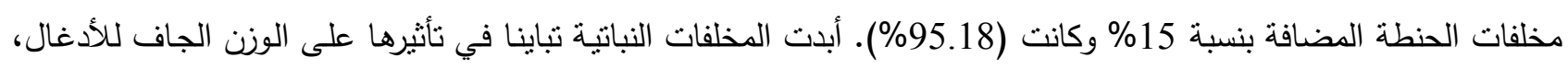

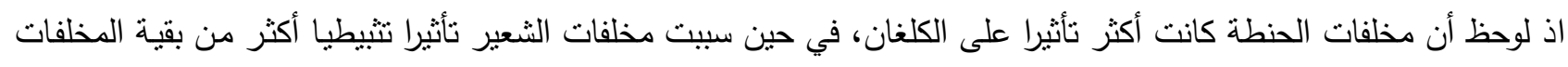
لدغل الحنيطة ولم تظهر المخلفات النباتية فروقات معنوية عند دغل الفران، كما وأظهرت مخلفات كل من الحنطة والثعير تأثنراً تثنبيطيا أعلى من مخلفات الذرة في الوزن الجاف لدغل ام الحليب. 
الجدول 3: تأثير المخلفـات النباتيـة لـ (الحنطـة، الشعير، الذرة الصففراء) في طول المجمسوع الجذري (سـم) لأدغـال (الكلغان، الحنيطة، ام الحليب، الفران).

\begin{tabular}{|c|c|c|c|c|c|c|}
\hline \multirow[b]{2}{*}{ لنسبة الإضبّفة } & \multirow[b]{2}{*}{ متوسط نسبة } & \multicolumn{3}{|c|}{ نوع المخلفات النباتية } & \multirow[b]{2}{*}{ الإضافة } & \multirow[b]{2}{*}{ 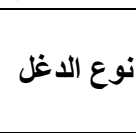 } \\
\hline & & الذرة الصفراء & الشعير & الحنطة & & \\
\hline 0.0 & $7 \mathrm{a}$ & $7 \mathrm{a}$ & $7 \mathrm{a}$ & $7 \mathrm{a}$ & مقارنة & \multirow{3}{*}{ الكلغان } \\
\hline 6.8 & $6.53 b$ & $6.7 \mathrm{a}$ & $6.3 \mathrm{a}$ & $6.6 \mathrm{a}$ & $\% 10$ & \\
\hline 8.2 & $5.73 c$ & $6.3 \mathrm{a}$ & $4.6 \mathrm{~b}$ & $6.3 \mathrm{a}$ & $\% 15$ & \\
\hline & & $6.66 \mathrm{a}$ & $5.96 \mathrm{~b}$ & $6.63 \mathrm{a}$ & \multicolumn{2}{|c|}{ تأثنير نوع المخلفات } \\
\hline 0.0 & $9.5 \mathrm{a}$ & $9.5 \mathrm{a}$ & $9.5 \mathrm{a}$ & $9.5 \mathrm{a}$ & مقارنة & \multirow{3}{*}{ الحنيطة } \\
\hline 32.7 & $6.4 \mathrm{~b}$ & $8.1 \mathrm{ab}$ & $6.1 \mathrm{bc}$ & $5.0 \mathrm{c}$ & $\% 10$ & \\
\hline 38.7 & $5.83 c$ & $6.3 b c$ & $6.8 \mathrm{bc}$ & $4.4 c$ & $\% 15$ & \\
\hline & & $7.96 a$ & $7.46 \mathrm{a}$ & $6.30 \mathrm{~b}$ & \multicolumn{2}{|c|}{ تأثثير نوع المخلفات } \\
\hline 0.0 & $6.0 \mathrm{a}$ & $6.0 \mathrm{a}$ & $6.0 \mathrm{a}$ & $6.0 \mathrm{a}$ & مقارنة & \multirow[b]{3}{*}{ ام الحليب } \\
\hline 39.0 & $3.66 \mathrm{~b}$ & $3.9 \mathrm{~b}$ & $3.3 \mathrm{~b}$ & $3.8 \mathrm{~b}$ & $\% 10$ & \\
\hline 48.4 & $3.1 \mathrm{~b}$ & $3.1 \mathrm{~b}$ & $2.7 \mathrm{~b}$ & $3.5 \mathrm{~b}$ & $\% 15$ & \\
\hline & & $4.33 \mathrm{a}$ & $4.00 \mathrm{a}$ & $4.43 \mathrm{a}$ & \multicolumn{2}{|c|}{ تأثثير نوع المخلفات } \\
\hline 0.0 & $5.05 \mathrm{a}$ & $5.05 \mathrm{a}$ & $5.05 \mathrm{a}$ & $5.05 \mathrm{a}$ & مقارنة & \multirow[b]{3}{*}{ الفران } \\
\hline 19.7 & $4.06 \mathrm{~b}$ & $4.3 \mathrm{ab}$ & $3.8 \mathrm{ab}$ & $4.1 \mathrm{ab}$ & $\% 10$ & \\
\hline 23.6 & $3.86 c$ & $3.7 \mathrm{ab}$ & $2.1 \mathrm{c}$ & $2.5 \mathrm{c}$ & $\% 15$ & \\
\hline & & $4.35 \mathrm{a}$ & $3.65 b$ & $3.88 \mathrm{~b}$ & \multicolumn{2}{|c|}{ تأثتير نوع المخلفات } \\
\hline
\end{tabular}

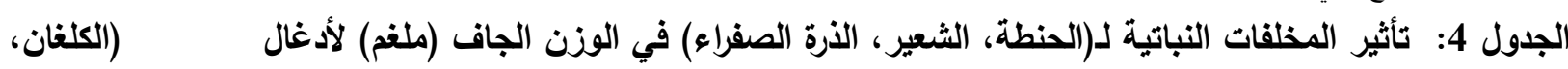
(الحنيطة، ام الحليب، الفران).

\begin{tabular}{|c|c|c|c|c|c|c|}
\hline \multirow{2}{*}{ لنسبة الاضتبيطة } & \multirow{2}{*}{ متوسط نسبة } & \multicolumn{3}{|c|}{ نوع المخلفات النباتية } & \multirow{2}{*}{ الإضافة } & \multirow{2}{*}{ وع الدغل } \\
\hline & & الذرة الصفراء & الشعير & الحنطة & & \\
\hline 0.0 & $0.445 \mathrm{a}$ & $0.445 \mathrm{a}$ & $0.445 a$ & $0.445 \mathrm{a}$ & مقارنة & \multirow{3}{*}{ الكلغان } \\
\hline 54.7 & $0.202 b$ & $0.202 \mathrm{c}$ & $0.283 b$ & $00.123 \mathrm{e}$ & $\% 10$ & \\
\hline 73.5 & $0.118 \mathrm{c}$ & $0.111 \mathrm{f}$ & $0.112 \mathrm{f}$ & $0.133 \mathrm{~d}$ & $\% 15$ & \\
\hline & & $0.252 \mathrm{~b}$ & $0.280 \mathrm{a}$ & $0.233 \mathrm{c}$ & \multicolumn{2}{|c|}{ تأَثير نوع المخلفات } \\
\hline 0.0 & $0.145 a$ & $0.145 a$ & $0.145 \mathrm{a}$ & $0.145 \mathrm{a}$ & مقارنة & \multirow{3}{*}{ الحنيطة } \\
\hline 48.3 & $0.075 b$ & $0.090 \mathrm{~b}$ & $0.016 \mathrm{~d}$ & $0.120 \mathrm{e}$ & $\% 10$ & \\
\hline 85.6 & $0.021 \mathrm{c}$ & $0.0480 \mathrm{c}$ & $0.009 \mathrm{f}$ & $0.007 \mathrm{~g}$ & $\% 15$ & \\
\hline & & $0.094 \mathrm{a}$ & $0.056 \mathrm{c}$ & $0.090 \mathrm{~b}$ & \multicolumn{2}{|c|}{ تأثتير نوع المخلفات } \\
\hline 0.0 & $0.037 \mathrm{a}$ & $0.037 \mathrm{a}$ & $0.037 \mathrm{a}$ & $0.037 \mathrm{a}$ & مقارنة & \multirow{3}{*}{ ام الحليب } \\
\hline 75.7 & $0.009 \mathrm{~b}$ & $0.016 \mathrm{~b}$ & $0.005 \mathrm{~d}$ & $0.007 \mathrm{c}$ & $\% 10$ & \\
\hline 83.8 & $0.006 \mathrm{c}$ & $0.008 \mathrm{c}$ & $0.007 \mathrm{c}$ & $0.005 \mathrm{~d}$ & $\% 15$ & \\
\hline & & $0.020 \mathrm{a}$ & $0.016 \mathrm{~b}$ & $0.016 \mathrm{~b}$ & \multicolumn{2}{|c|}{ تأتثير نوع المخلفات } \\
\hline 0.0 & $0.014 \mathrm{a}$ & $0.014 a$ & $0.014 \mathrm{a}$ & $0.014 \mathrm{a}$ & مقارنة & \multirow{3}{*}{ الفران ل } \\
\hline 35.8 & $0.009 \mathrm{~b}$ & $0.007 \mathrm{~d}$ & $0.010 \mathrm{~b}$ & $0.010 \mathrm{~b}$ & $\% 10$ & \\
\hline 42.9 & $0.008 b c$ & $0.009 b c$ & $0.007 \mathrm{~d}$ & $0.008 \mathrm{~cd}$ & $\% 15$ & \\
\hline & & $0.010 \mathrm{a}$ & $0.010 \mathrm{a}$ & $0.010 \mathrm{a}$ & \multicolumn{2}{|c|}{ تأثنير نوع المخلفات } \\
\hline
\end{tabular}




$$
\text { وسن صالح حسين وآخرون }
$$

يظهر الثكل (1) انخفاض في عدد الأوراق للادغال النامية في التربـة الحاويـة على مخلفات (الحنطة والثعير والذرة) مقارنة مع عدد الأوراق للادغال النامية في تربة المقارنة (بدون مخلفات) وكانت أعلى نسبة اختزال في عدد الأوراق لدغل الحنيطة

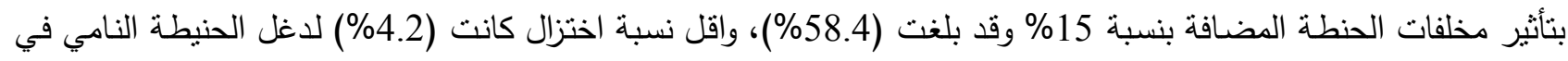
التربة الحاوية على مخلفات الذرة وبنسبة إضافة 15\% بيتضح من الثكل (2) حدوث اختزال في المساحة الورقية للأدغال الأربعة المدروسة وكان التركيز 15\% أكثر تاثيراً في اختزالا المساحة الورقية في معظم المعاملات، ولوحظ ان أعلى نسبة اختزال كانت

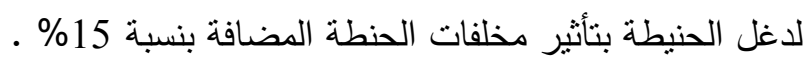

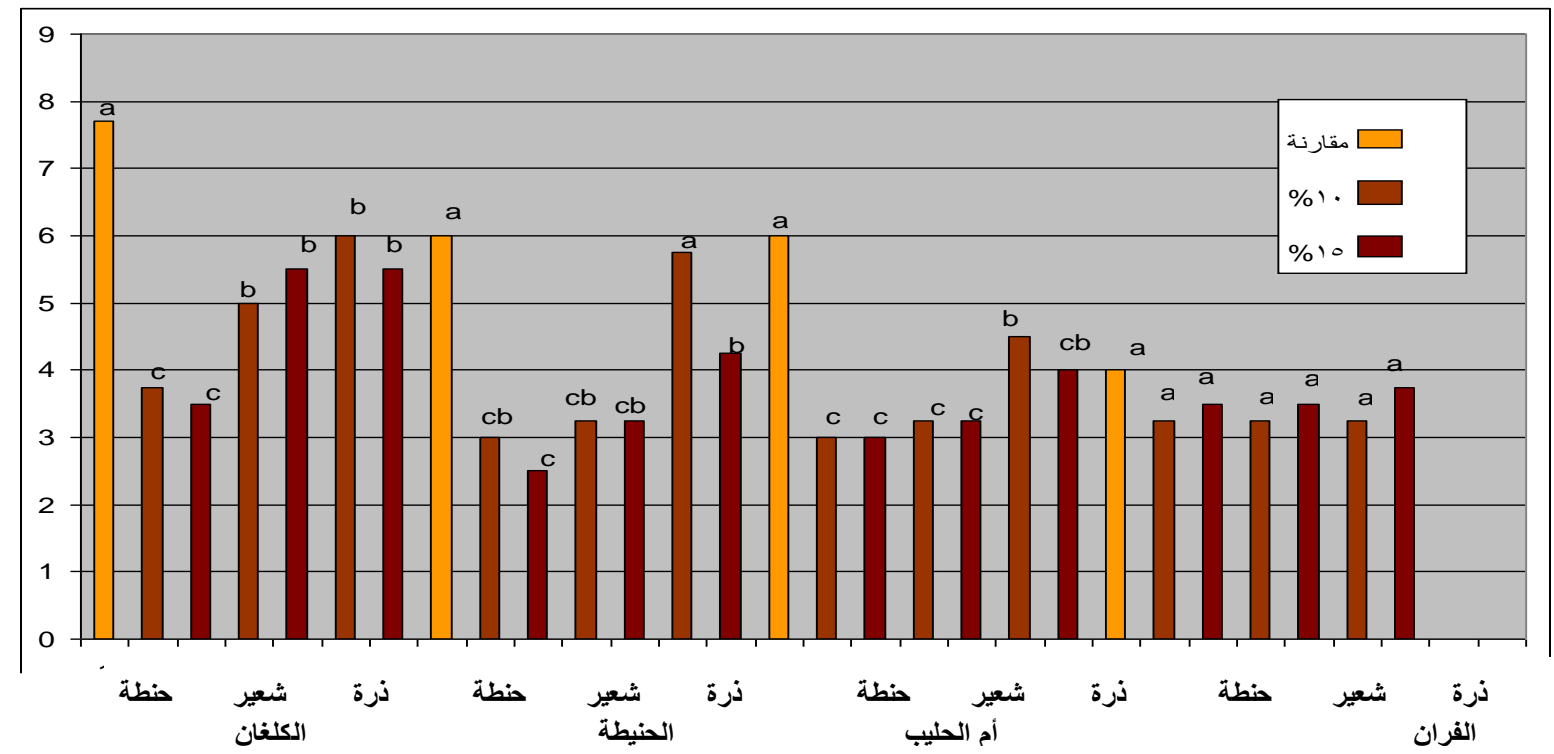

الثكل 1: يبين تأثير المخلفات النباتية (الحنطة، الثعير، الذرة الصفراء) في عدد الأولق للأدغال المدروسة

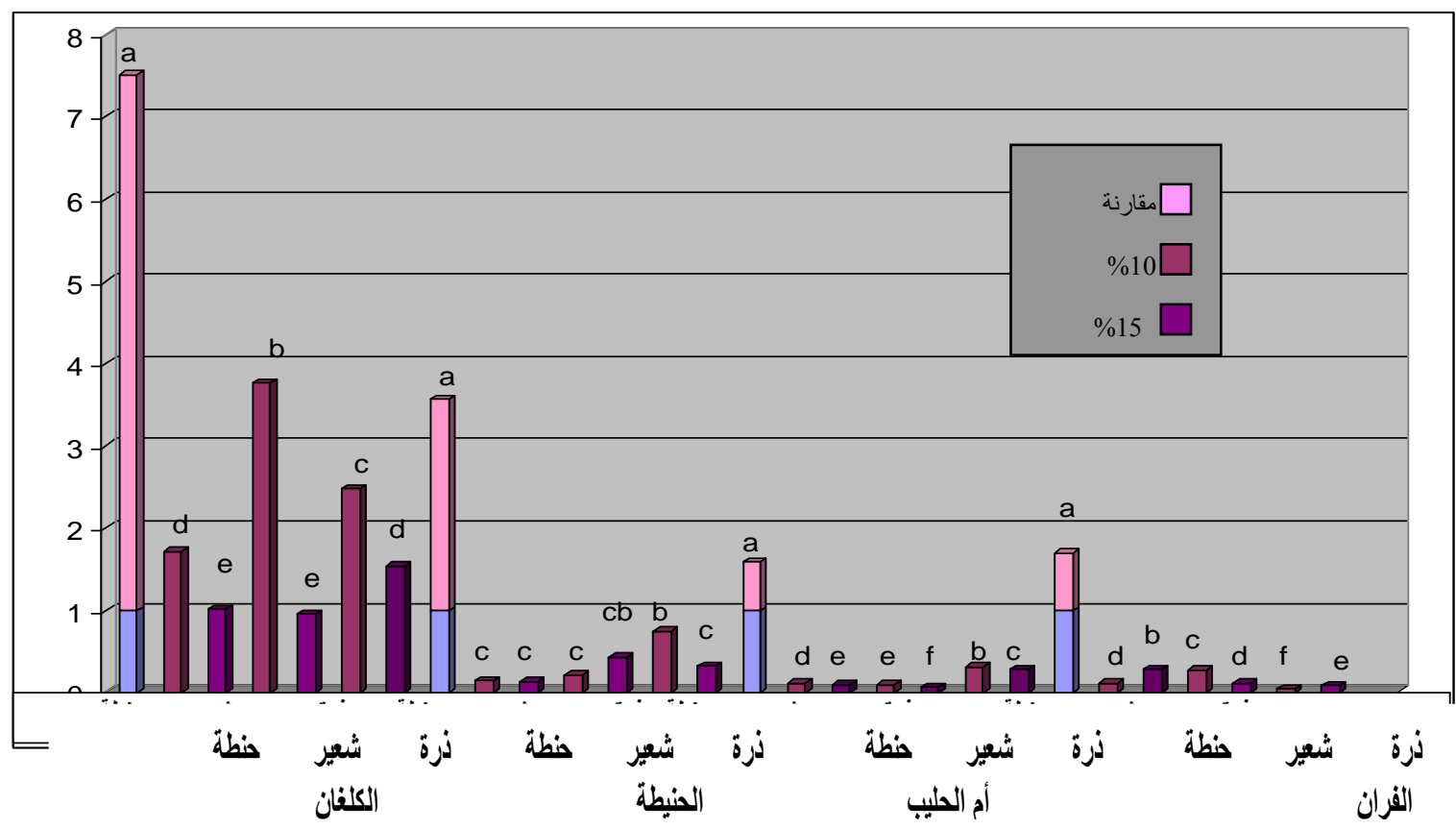

الثكل 2: يبين تأثير المخلفات النباتية (الحنطة، الثعير، الذرة الصفراء) في المساحة الورقية (سم²) للادغال المدروسة 
أشثارت الكثوفات الأولية للتحري عن وجود المركبات الفعالة في المجاميع الخضرية لـ (الحنطة، الثعير ، الذرة الصفراء) كما

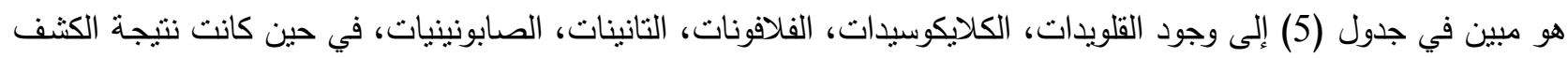
عن الستيرويدات سالبة، أما الكثف عن التربينات فكانت موجبة لمخلفات الثعير والذرة (بنسبة اكبر) وسالبة في المخلفات النباتية

للحنطة.

الجدول 5: الكثف الأولي عن المركبات الكيمائية الثانوية في المخلفات النباتية لـ (الحنطة، الشعير، الذرة).

\begin{tabular}{|c|c|c|c|}
\hline الذرة & الثعير & الحنطة & المركبات الكيمائية \\
\hline+ & + & + & الكلايكوسيدات \\
\hline+ & + & + & القلويدات \\
\hline+ & + & + & الفلافونات \\
\hline++ & + & - & التربينات \\
\hline+ & + & + & التانينات \\
\hline- & - & - & الستيرويدات \\
\hline+ & + & + & الصابونينات \\
\hline
\end{tabular}

\section{المناقشة}

ان الاختزال في أنبات البذور والنمو للأدغال (الكلغان، الحنيطة، ام الحليب، الفران ) بتأثثر المخلفات النباتية لهحاصيل (الحنطـة، الثـعير، الذرة الصفراء) والمحضـنة لمدة أسبوع قد يعزى إلى المركبات الاليلوباثيـة المتحررة إلى التربـة مـن مخلفات المحاصيل المضافة الى التربة والتي من الممكن ان نتراكم فيها نتيجة لعملية الغسيل Leaching او عن طريق تحلل المخلفات

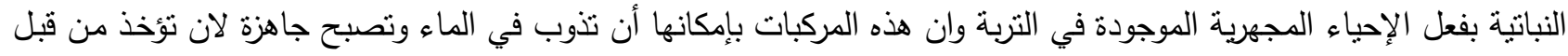
النبات وتحدث ضررا فيه، بحيث تصل إلى التركيز المؤثر مسببة تأثنرا في إنبات البذور ونمو نباتات الأدغال المزروعة في تلك باءه التربة، كما ان سبب التثبط في الإنبات قد يعزى إلى تأثنر تلك المركبات في بعض الانزيمات التي تسهم في تحلل بعض المواد

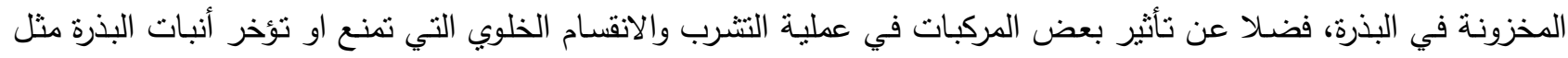
مركبي (Camphor, Cineol) والتي تكون مثبطـة للانقسـام الخلوي (Macias, 2002). وتنقف هذه النتائج مـع ماوجده Ghafarbi et al., (2012) بان بذور الحنطة سببت انخفاضاً في نسبة أنبات البذور وطول الجزء الخضري والجذري لاغلي

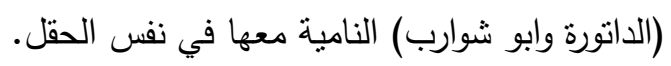

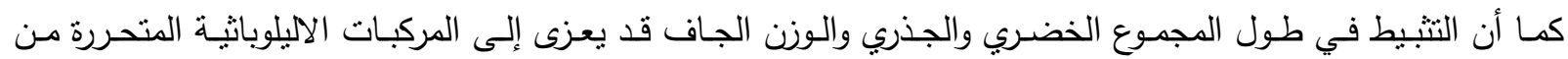
المخلفات النبانية للمحاصيل المدروسة حيث لوحظ تباين في تأثنرها باختلاف أنواع الأدغال ونسب الإضافة لتلك المخلفات، وان ان

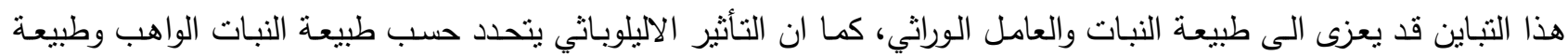
المركبات المتحررة وتركيزها وحساسية الجزء النباتي (سعيد، 2010)، و تعمل هذه المركبات على تتبيط طول المجموع الجذري، إذ إذي قد تؤثر على الإنزيمات وتقلل فعاليتها و لربما ارتبطت بإنزيمات خاصة بالتقاعلات الوسطية المؤدية لتكوين الاوكسين مما يؤدي

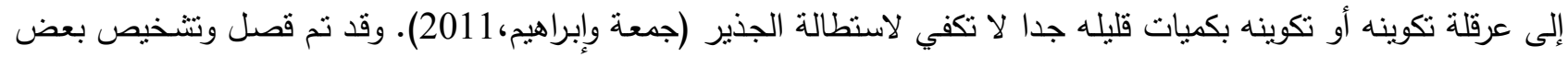

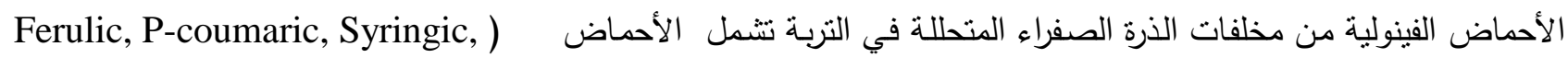
Vanillic)، (المزوري، 1996) وأنثار البرهاوي، (1997) إلى احتواء مخلفات الحنطة على بعض المركبات الفينولية والتي قد يعزى إليها التأثنر التثبيطي على الأدغال. 


$$
\text { وسن صالح حسين وآخرون }
$$

ان الاختلاف في تأثثير نسب الإضافة (15,10\%) قد يعزى سبب ذلك الى ان المركبات الاليلوباثية التي تتبط نمو بعض

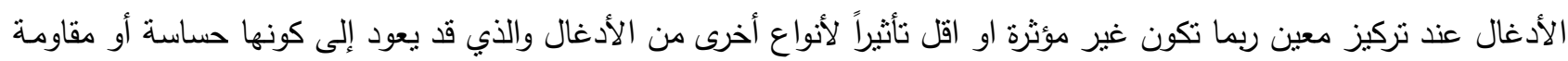

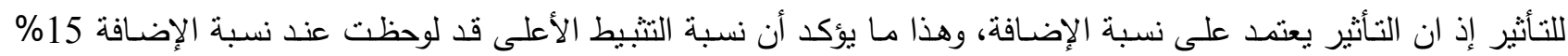

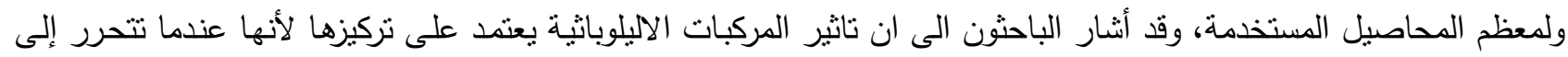

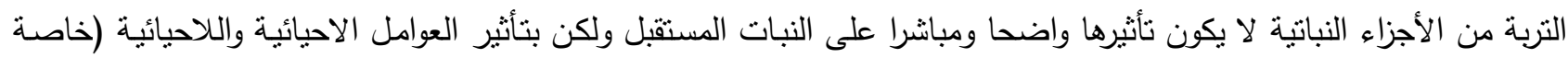

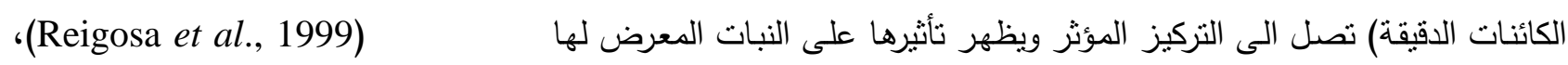

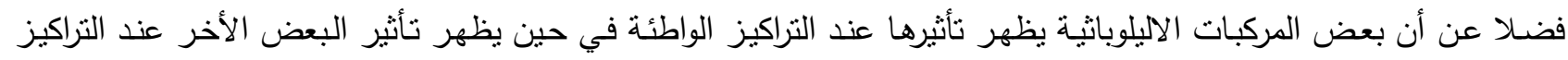

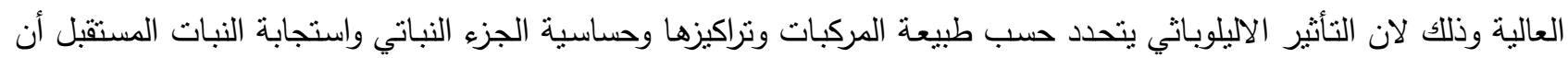

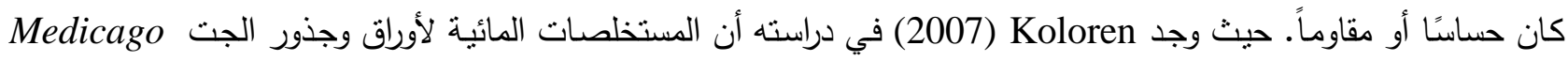
( Vicia craccal L. و sativa L. ولاحظ (Amaranthus retroflexus,Lolium perenne L.,Pomoea hederacea L., Portulaca aleracea L. ازدياد نسبة التثيط بزيادة التركيز • وعن تأثثر المخلفات النباتية في المساحة الورقية وعدد الأوراق لوحظ اختزال واضح وان سبب

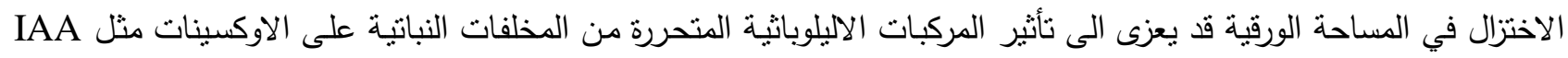
مـا أدى إلى اختزال المساحة الورقية وتتفق هذه النتائج ميع نتائج (2001) ميث ذكر ان المستخلصات المائية

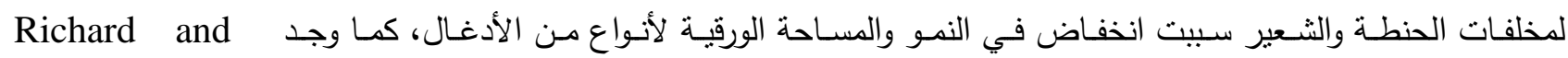
Euphorbia esula ثبط المساحة الورقية واثر في نفاذية الأغشية لـ Caffeic acid بان مركب لـ اعن الـ Christopher, (2000)

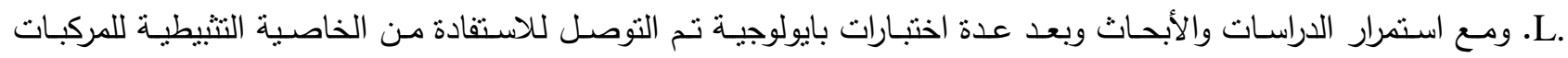
الاليلوباثيـة في السبطرة البايولوجيـة على الأدغال وإنتاج مبيدات طبيعيـة بالاستفادة مـن هذه المنتجـات الطبيعيـة، وقد أثنارت

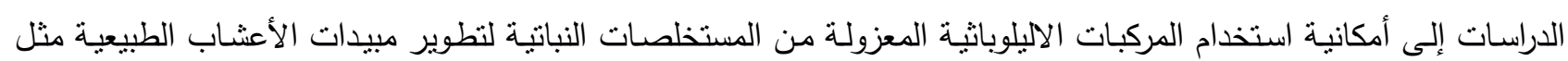
الـ Coumarin و النيكوتين( Isman, 2006 ) وبما ان المركبات الاليلوباثية هي نواتج أيض ثانوية تبنى داخل النبات خلال فترة نموه والتي تتضمن القلويدات (Flavnoids, Phenolics, Terpendis,

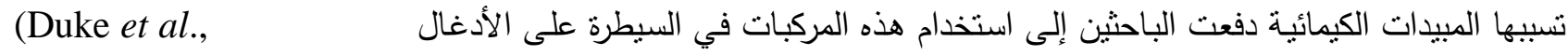
2000 ; Jabran et al., 2010b) البيئة.(Singh et al., 2003; Farooq et al., 2008; Hussain, et al., 2007). وقد أنشارت الكشوفات الأولية للتحري عن وجود المركبات الفعالة في المخلفات النباتية للمحاصيل الثلاثة إلى وجود مركبات

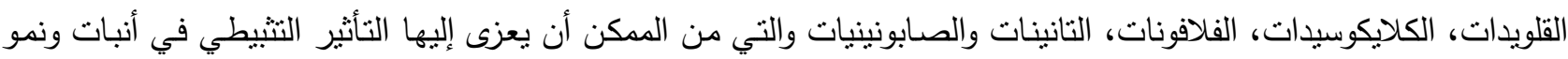

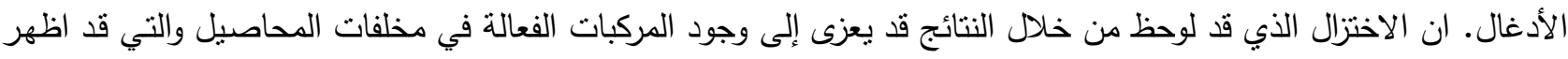
الكثف عن وجودها في مخلفات المحاصيل (الحنطة، الثعير، الذرة الصفراء) وهذا قد يبرر التباين في التأثير لمخلفات المحاصيل الثلاثة. والتي أثنارت الدراسات إلى إمكانية تحولها إلى مركبات أبسط او أعقد تركيبا بعد تحررها إلى التربة. إذ تحتوي المخلفات

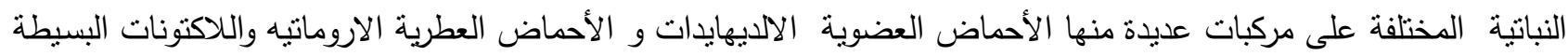
غير المشبعة ولكومارينات ولكينونات، والفلافونويدات والتانينات والقلويدات والتربينويدات والستيرويدات فضلا عن بعض التهات الغازات السامة (Putnan, 1987). ويؤيد ذلك الدراسة التي أجريت من قبل (2009) , Mahmood et al بان المستخلص المائي للذرة

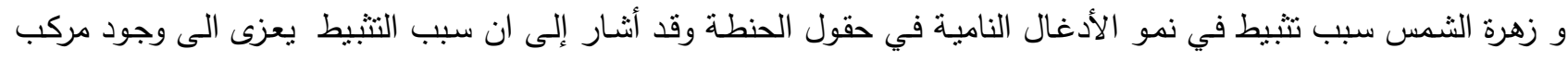

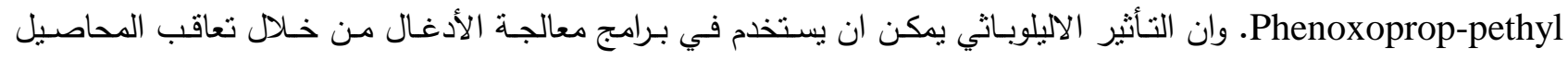


والتداخل فيما بينها كذلك عن طريق رش هذه الأدغال بالمستخلصات المائية لمخلفات تلك المحاصيل Bhowmik and) (أنثارت نتائج الدراسة إلى اختلاف الأدغال في استجابتها للمعاملة (التأثنر التثبطي) لمخلفات المحاصيل وهذا ربما يعود إلى طبيعة النبات والعامل الوراثي.

\section{المصادر العربية}

جمعة ، نجم عبداله ؛ ابراهيم، نغم سعدون (2011). تأثثر المستخلصـات المائية والكحولية لنبات اليوكالبتوس في أنبات ونمو

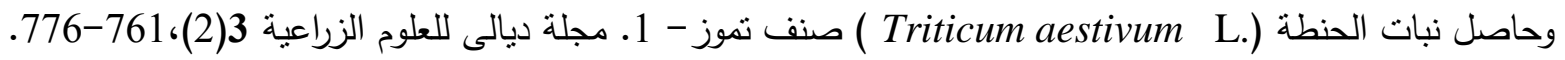

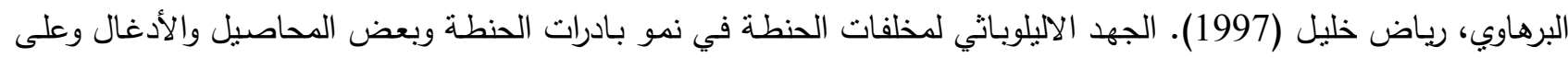

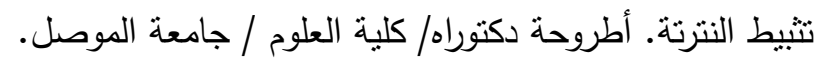

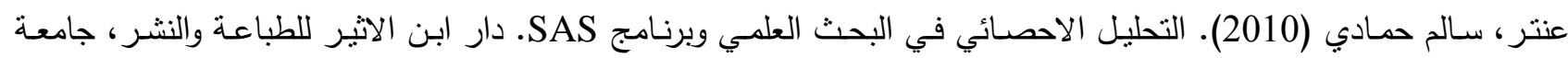
الموصل.

سعيد، جنان عبدالخالق (2009). تأثنير التضاد الحيوي لمخلفات زهرة الثمس في أنبات البذور والنمو لثناثة انواع من الأدغال.

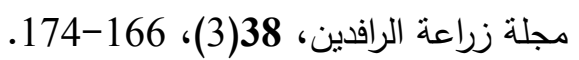

ال شاكر ، نادية محمد مهدي (2007). التداخلات البيوكيمائية لنبات السعد Cyperus rotundus مع بعض المحاصيل والاحياء

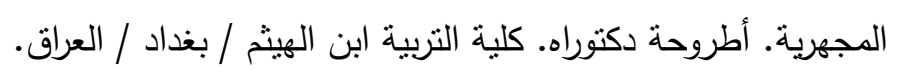

المزوري، حسن امين (1996). دراسات في الجهد الاليلوباثي للذرة الصفراء. أطروحة دكتوراه. كلية التربية (ابن الهيثم /جامعة لغراهة

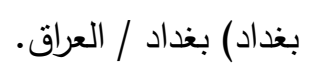

محمد، علي صادق؛ الدليمي، محمد عباس؛ ساعور ، كوكب يعقوب (2009). الكشف عن المركبات الكيمائية والتتقية الجزيئية للقلويدات في مستخلصات (تمار وأوراق وجذور) نبات عنب الذيب (Solanum nigrum). المجلة العراقية للعلوم. .314-303، (3)50

\section{المصادر الأجنبية}

Abbas, M.N.; Rana, S.A.; Shahid, M.; Rana, N.; Mahmood-ul-Hassan, M.; Hussain, M. (2012). Chemical evaluation of weed seeds mixed with wheat grins at harvest. J. Anim. Plant Sci. 22(2), 283-288.

An, M.; Prately, J.E.; Haig, T. (1997). Phytotoxicity of Vulpia residues I. Investigation of aqueous extracts. J. Chem. Eco., 23 (8), 1979-1995.

Bhowmik, P.C.; Inderjit, J. (2003). Challenges and opportunities in implementing allelopathy for natural weed management. Crop Prot., 22 (4), 661-671.

Chung, I.M.; Ahn, J.K.; Yun, S.J. (2001). Assessment of allelopathic potential of coastal bermudagrass. Agron. J., 80, 557-560.

Duke, S.O.; Dayan, F.E.; Romagni, J.G.; Rimando, A.M. (2000). Natural products as sources of herbicide, current status and future trends. Weed Res., 40, 99- 111.

Farooq, M.; Jabran, K.; Cheema, Z.; Wahid, A.; Siddique, H.M.K. (2011). The Role of Allelopathy in Agricultural Pest Management. Pest Management Sci., 67, 493-506.

Farooq, M.; Jabran, K.; Rehman, H.; Hussain, M. (2008). Allelopathic effects of rice on seedling development in wheat, oat, barley and berseem. Allelopathy J., 22 (2), 385-390.

Ghafarbi, S.P.; Hassannejad S.; Lotfi, R. (2012). Seed to seed allelopathic effects between wheat and weeds. J. Agriculture crop Sci., 4(22),1660-1665.

Goran, Y.A.; Sakri, F.A. (2009). Allelopathy effect of Barley(Hordeum vulgare L.) water extract of shoot, root and soil beneath plant on seed germination and seedling of wheat,barley cultivars and some weeds. J. Sci., 21(4). 


$$
\text { وسن صالح حسين وآخرون }
$$

Haouala, R.; Narwal, S.S. (2013). Role of allelopathy in weed management for sustainable agriculture. Allelopathy. 217-249.

Harborne, J.B. (1973). "Phytochemical Methods". London. Chapman and Hall, Ltd. pp. 49-188.

Heidarzade, A.; Pirdashti, H.; Esmaeili, M. (2010). Quantification of allelopathic substances and inhibitory potential in root exudates of rice (Oryza sativa L.) varieties on Barnyard grass (Echinochloa crus-galli L.). Plant Omics. J., 3, 204-209.

Hesammi, E.; Farshidi, A. (2012). A study of the allelopathic effect of wheat residue on weed control and growth of vetch (Vigna radiata L.). Advances in Environmental Biology 6, $1520-1522$.

Hussain, S.; Siddiqui, S.U.; Khalid, S.; Jamal, A.; Qayyum, A.; Ahmed, Z. (2007). Allelopathic potential of senna on germination and seedling characters of some major serial crops and their associated grassy weeds. Pak. J. Bot. 39 (4), 1145-1153.

Isman, M.B.(2006). Botanical insecticides, deterrents, and repellants in modern agriculture and an increasingly regulated world. Annual Review of Entomology. 51, 45-66.

ISTA. (1976). Intension rules for seed testing. Seed Sci. and Tech. 34.

Jabran, K.; Farooq, M.; Hussain, M.; Rehman, H.; Ali, M.A. (2010). Wild oat (Avena fatua L.) and canary grass (Phalaris minorRitz.) management through allelopathy. J. Plant Prot. Res., 50 (1), 32-35.

Koloren, O. (2007). Allelopathic effects of Medicago sativa L. and Vicia cracca L. leaf and root extracts on weeds. J. Bio.Sci., 10(10),1639-1642.

Macias, F.A. (2002). Bioactive terpinoids from sunflower leaves cv. Peredovick. Phytochemistry, 61, 687-692.

Mahmood, k.; Khan, M.B.; Hussain, M.; Gorchani, M.A. (2009).Weed management in wheat (Triticum aestivum L. ) using allelopathic crop water extracts. Internalional J. Agri. and bio., 11,751-755.

Naseem, M.; Aslam, M.; Ansar, M.; Azhar, M. (2009). Allelopathic effects of sunflower water extract on weed control and wheat productivity. J. Weed Science Research, 15, 107-116.

Putnan, A.R. (1987). Allelopathic chemical natures herbicides action. Chem. Eng.,4,3435.

Refreshing, A.S. (2001). Residual effect of barley, wheat, oilseed rape on weed. Seventh Iranian Crop Sciences Congress, 654.

Reigosa, M.J.; Moveivars, S.A.; Gonzalez, L. (1999). Ecophysiological Approach in Allepathy in critical reviews in plant Sciences, 8 (5), 577- 608.

Richard, B.; Christopher, K. (2000). "The Effect of Caffeic Acid on Root Cell Membrane Potentials in Leafy Spurge (Euphorbia esula L.)". (Professional Communications). Proceedings of the North Dakota Academy of Science

Roopashree T.S.; Dang, R.H.; Rani, S.; Narendra, C. (2008). Antibacterial activity of antipsoriatic herbs: Cassia tora, Momordica charantia and Calendula officinalis. International J. App. Res. Nat.l Prod., 1, 20-28.

Samad, M.A.; Rahman, M.M.; Hussain, A.K.; Rahman, M.S.; Rahman, S.M. (2008). Allelopathic effects of five selected weed species on seed germination and seedling growth of corn. $J$. Soil Natural, 2, 13-18.

Singh, H.P.; Batish, D.R.; Kohli, R.K. (2003). Allelopathic interactions and allelochemicals: new possibilities for sustainable weed management. Crit. Rev. Plant Sci., 22 (3-4), 239-311.

Weih, M.; Didon, U.M.; Wastljung, A.C.; Bjorkman, C. (2008). Integrated agricultural research and crop breeding: Allelopathic weed control in cereals and long-term productivity in perennial biomasscrops. Agric. Syst. 97, 99-107. 